\title{
Accessibility concepts and indicators in transportation strategic planning issues: theoretical framework and literature review
}

\author{
Ana VULEVIC 1 \\ IInstitute of Transportation CIP, Department of Architecture and Urban Planning, Belgrade, Serbia
}

\begin{abstract}
Accessibility is a well-known and studied concept within the scientific literature. Good transportation accessibility is certainly an important factor in exploiting spatial potentials. The quality of transportation infrastructure in terms of capacity, travel speed, connectivity etc., determines the quality and advantage of a location relative to other locations, which is usually measured as accessibility. Increasingly overloaded transport corridors, in the context of changing transportation flows are becoming an important issue for accessibility. This Paper gives a very brief overview of which kind of transportation networks and services indicators should be used in relevant documents and in transportation planning practice. This Paper provides a comprehensive overview of the different definitions, dimensions and indicators of accessibility in the literature of those already discovered.
\end{abstract}

Key words-Accessibility indicators, accessibility, transportation network and services indicators

\section{INTRODUCTION}

The interrelations between regional development, spatial analysis and transportation are strong and both approaches, the spatial and transport, opposite must be combined in a more efficient way [10]. Accessibility is a frequently used concept, but there is no consensus about its definition and formulation. A large amount of research and working papers about transport accessibility issues is produced over the years. New studies and practical approaches are continuously emerging on this subject. Accessibility was commonly defined as the ease with which activities can be reached from a certain place and with a certain system of transportation [24; 32]. The concept generally takes the combination of two elements into account: the location on a surface relative to suitable destinations, and the characteristics of the transport network [34]. Accessibility as an issue has an important role in the European Observation Network, Territorial Development and Cohesion. It provides a wide range of indicators that describe the transport system and its spatial implications to enhance the decision support tool so that policy makers can more easily find the relevant equation between policy objectives and transport policy measures [2]. This Paper gives a very brief overview of which kind of transportation networks and service indicators should be used in relevant documents and Transportation Planning Strategies. The starting points are indicators like the quality of transportation infrastructure in terms of capacity, connectivity, travels speeds etc. Also, the more complex indicators of accessibility are presented. The concept of accessibility as baseline for territorial indicators is introduced.

\section{ACCESSIBILITY: THEORETICAL FRAMEWORK AND REVIEW OF LITERATURE}

"Accessibility is the main "product" of a transportation system. It determines the locational advantage of an area (a region, a city or a corridor) relative to all areas (including itself") "[10]. Indicators of accessibility measure the benefits that households and firms in an area enjoy from the existence and use of the transportation infrastructure relevant for their area.

The important role of transportation infrastructure for spatial development in its most simplified form implies that areas with better access to the locations of input materials and markets will ceteris paribus, be more productive, more competitive and hence more successful than more remote and isolated areas [see 10].

However, the impact of transportation infrastructure on spatial development has been difficult to verify empirically. There seems to be a clear positive correlation between transport infrastructures endowment or the location in interregional networks and the levels of economic indicators such as 
GDP per capita [6; 7; 8]. However, this correlation may merely reflect historical agglomeration processes rather than causal relationships effective today [19]. Attempts to explain changes in economic indicators, i.e. economic growth and decline, by transport investment have been much less successful. The reason for this failure may be that in countries with an already highly developed transport infrastructure further transport network improvements bring only marginal benefits. The conclusion is that transport improvements have strong impacts on regional development only where they result in removing a bottleneck $[5 ; 6 ; 40]$.

While there is uncertainty about the magnitude of the impact of transport infrastructure on spatial development, there is even less agreement on its direction. It is debatable whether transportation infrastructure contributes to spatial polarization or decentralization. Some analysts argue that regional development policies based on the creation of infrastructure in lagging regions have not succeeded in reducing regional disparities in Europe [35], whereas others point out that it has yet to be ascertained that the reduction of barriers between regions has disadvantaged peripheral regions $[6 ; 7 ; 8]$. From a theoretical point of view, both effects can occur.

A large number of studies and working papers about transportation accessibility issue is produced over the years. New studies and practical approaches are continuously emerging on this subject. In this section, we present a compilation of the most representative approaches to the study of transport accessibility and an overview of relevant concepts. Numerous authors have also analyzed the relationship between transport infrastructure accessibility and economic prosperity. Some studies show that transport infrastructure investments can both have positive (increased population or gross product) and negative economic impacts (degradation of the region, because firms and residents can move away from the region more easily) $[1 ; 18]$. Transport infrastructure investments positively influence an area's economic growth if three conditions met: it increases accessibility within a region, transport is a relevant input for the processes of the firms in the area, and the infrastructure does not generate significant negative environmental externalities [16]. Thompson and Taniguchi (2001) conclude that the construction of transportation infrastructure (increasing accessibility) leads to employment growth and lower consumer prices of commodities at the city level [33]. The effects at the state level was addressed address by Jiwattanakulpaisarn et al. (2010) indicate that lane-mile additions of own-state major highways could increase state employment growth in the services sector while reducing growth in manufacturing. However, the causal relationship has also found to work the other way around [31]. Gutierrez et al. (2010) considered how different approaches have been used to measure regional spillover effects and proposed a new methodology based on GIS and accessibility indicators to measure spatial spillovers of transport infrastructure investment [22]. Karou and Hull (2014) outlined the concept and methodology of a Spatial Network Analysis of Public Transport Accessibility (SNAPTA) model for measuring the accessibility by public transport to different urban services and activities, and presented the findings related to this pilot study with a focus on changes in potential accessibility to jobs between four different public transport network scenarios [37]. There have been numerous studies that have examined changes in rail accessibility as a result of the introduction of high-speed rails, particularly at the European scale. However, the results of these studies depend on the nature of the accessibility measure used, the nature of the high-speed rail implementation and the area of study [20]. Several authors presented a Geographical Information System (GIS)-based methodology, which analyses changes in the territorial distribution of accessibility resulting from high-speed rail investments. It has been estimated that the implementation of a European network of high speed trains could reduce weighted travel times between major European cites by as much as 50\% [23]. Implementation of a single international line would have a much smaller effect across Europe - reducing weighted travel costs by $5 \%$ or increasing a market potential measure of accessibility by $2 \%$ [22]. If the study is done at a national scale, a new high-speed line might reduce rail travel times by $10 \%$ or lead to a broadly similar increase in market potential measures [9]. Several authors have analysed the impact of HSR in Europe using centrality indicators, including Bruinsma and Rietveld (1993), Spiekermann and Wegener (1996), Gutiérrez et al. (1996) and Gutiérrez (2001) [11;26;23;21]. In general, these studies show differences in accessibility between regions rather than within regions. Where impedance functions are used, steeper impedance functions generally lead to more variation on a lower spatial scale. Some authors analyzed the influence of accessibility on labor supply [17; 18; 25]. A common approach is to assume that individuals allocate their total daily hours between work and non-work activities. Hence, reduced travel time will result in more time available for both work and leisure time activities. Given assumptions on work/leisure time substitution as well as on the income effect from reduced travel times and costs, improved accessibility has a positive effect on the amount of labor that individuals are willing to supply [12]. 
Regarding population, Chi (2010) examines the role that highway expansion plays in the process of population change [13]. The author proposes an integrated spatial regression approach to study the impacts of highway expansion on population change in the 1980s and 1990s in Wisconsin at the minor civil division level. The findings suggest that the impacts of highway expansion on population change differ across rural, suburban, and urban areas: there are only indirect effects in rural areas, both direct and indirect effects in suburban areas, and no statistically significant effects in urban areas. In addition, Chi (2012) shows that airport accessibility and highway improvement promote population growth in rural areas [14]. In suburban areas, airport accessibility promotes population growth, while highway accessibility facilitates migration of population out of the area. In urban areas, highways and airports have no significant effect on population growth. Chi $(2010,2012)$ argues that in urban areas, infrastructure development reaches maturity, meaning that extra investments do not result in growth or development of the area [13; 14]. Koopmans et al. (2012) examined the impact of accessibility improvements on municipal population growth in the Netherlands between 1840 and 1930, using census data [3]. By mapping a multimodal transport network and calculating the shortest travel time between all municipalities, authors generated an accessibility indicator, which is strongly influenced by railway connections. The regressions show that high rail accessibility levels positively related to municipal population growth from 1880 onwards.

The importance of road transport infrastructure in the location decision of firms studied and analyzed the influence of road transport and other factors on industrial location in terms of the exante decision-making process. Based on conditional logit models and recent census data, Hong [40], studied the influence of transport and other factors on the location of foreign logistics firms across Chinese cities. The results of this research suggested that the location of foreign logistics firms depended on transport conditions in terms of roadway, railway and waterway, as well as market size, labor quality, agglomeration economies and government incentives. The importance of transport was found to vary with some firm-specific characteristics.

Accessibility is not easy to quantify, and there is no best approach to measuring it [21]. In the scientific literature, accessibility measurements have generally been use to evaluate the performance of transport networks. The measurement of accessibility also plays a key role in evaluating the competitive advantage of some locations due to the quality of their transport infrastructure. Handy and Niemeier (1997) classified the available measures into three categories: isochrones (which indicate the number/proportion of destinations reachable within a given travel time/distance/ cost from an origin), gravity-based measures (which assume a gradual decrease in accessibility as the travel time to destinations increases) and utility-based measures (which estimate the accessibility at the individual level) [36]. Another classification was established by Geurs and Ritsema van Eck (2001) and Geurs and van Wee (2004), who suggested four basic perspectives: (1) infrastructure-based measures, (2) activity-based measures, (3) person-based measures and (4) utility-based measures [27; 28].

\section{INDICATORS OF TRANSPORT NETWORK, SERVICES AND ACCESSIBILITY}

\section{A. Indicators of transport infrastructure supply}

Endowment indicators consider the transport infrastructure in an area expressed by such measures as total length of motorways or number of railway stations. The indicators most frequently used are "density of infrastructure" ( $\mathrm{km}$ of motorways or motorways per surface or number of inhabitants) or "connectivity to transport terminals" (generalized cost to get motorways entrances, railways stations etc.). These indicators are able to capture the capacity of the infrastructure independently from the services actually provided by transport carriers and their quality, and the utility they provide to fulfil the development opportunities of the region.

The basic data needed to calculate this type of indicators are multimodal transport networks at European level, precise enough in terms of intermodal connections and location of transport terminals, with information concerning infrastructural characteristics [2].

List of indicators includes:

- $\quad$ Length/density of roads by road category

- Length/density of railways by railway category

- Number of ports

- Number of airports

- Generalized cost to motorway entrances by road 
- Generalized cost to railway stations by road

- Generalized cost to airports by road

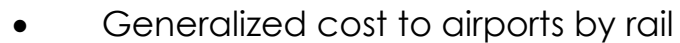

- $\quad$ Generalized cost to ports and logistic centres by road

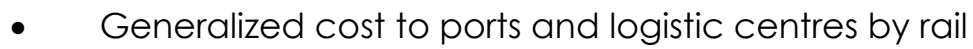

Transport infrastructure capacity indicators can be grouped in two basic types, one describing capacities of links, the other capacities of terminals.

Existing indicators of transport infrastructure capacity:

- $\quad$ Link capacity Capacity of road

- Capacity of railway track

- Capacity of ferry link

- $\quad$ Node capacity Capacity of road nodes (intersections, tollbooth)

- Capacity of airport by category

- Capacity of port by category

- Capacity of intermodal terminals

Existing indicators of transport services:

- Number of departing/arriving trains by category and destination

- Number of departing/arriving flights by destination

- Number of departing/arriving ferries by destination

- Number of passenger cars

- Number of public transport vehicles by type

- Number of goods vehicles by type

- $\quad$ Link travel time by transport mode or multimodal

- $\quad$ Origin-destination travel time by transport mode or multimodal

- $\quad$ Link travel cost by transport mode or multimodal

- Origin-destination travel cost by transport mode or multimodal

- $\quad$ and type of traveller

Indicators of network vulnerability include:

- Geographic structural vulnerability of corridors

- Climatic vulnerability of corridors

B. Indicators for the actual use of transport networks and services

Indicators for the actual use of transport networks and services which are used in relevant documents and studies: traffic volumes and flows and traffic flow indicators. A distinction is made between traffic indicators showing volumes on links or in nodes and flow indicators which always include origin and destination of the flows.

The measure of volumes and flows in and out from a given place to all others already is an indicator of the actual accessibility, not related to the transport system by itself but to the integration of a region in a larger economic area. Actual traffic volumes and flows encapsulate other accessibility elements beyond the transport system such as cultural relations, language barriers, institutional cooperation.

List of traffic volume and flow indicators includes:
- $\quad \mathrm{Km}$ per person per mode by purpose
- $\quad \mathrm{Km}$ per ton by goods type per mode
- Traffic on road links by vehicle type
- Number of trains and passengers on rail links
- Number of passengers and freight, cars and lorries on ferries
- $\quad$ Traffic volume (passenger and freight) of airports
- $\quad$ Traffic volume (passenger and freight) of ports
- $\quad$ Traffic volume (freight) in intermodal terminals
- $\quad$ Passenger flows by user type, trip purpose 
Logistics \& Sustainable Transport

Vol. 7, No. 1, October 2016, 58-67

doi: 10.1515/jlst-2016-0006

- Goods flows by type of good

- $\quad$ Flows with origin and destination in different areas by modes

Traffic flow indicators are different from traffic volume indicators as they always include origin and destination, i.e. the relationship between two different points in space:

- $\quad$ Traffic flow Passenger flows by user type, trip purpose

- $\quad$ Trade/goods flows by type of good

\section{Accessibility indicators}

There are numerous definitions and concepts of accessibility. A general definition is that "accessibility indicators describe the location of an area with respect to opportunities, activities or assets existing in other areas and in the area itself, where 'area' may be a region, a city or a corridor" [5]. Accessibility indicators can differ in complexity. More complex accessibility indicators take account of the connectivity of transport networks by distinguishing between the network itself and the activities or opportunities that can be reached by it. These indicators always include in their formulation a spatial impedance term that describes the ease of reaching other such destinations of interest. Impedance can be measured in terms of travel time, cost or inconvenience [2].

Accessibility indicators can be classifying by their specification of the destination and the impedance functions [1]:

- Travel cost indicators measure the accumulated or average travel cost to a predefined set of destinations. For instance, the average travel time to all cities of more than 500,000 inhabitants.

- Daily accessibility is based on the notion of a fixed budget for travel in which a destination has to be reached to be of interest. The indicator is derived from the example of a business traveller who wishes to travel to a certain place in order to conduct business there and wants to be back home in the evening [3]. Maximum travel times of between three and five hours one-way are commonly used for this indicator type.

- Potential accessibility. These most frequently applied and most extensively tested accessibility indicators are potential indicators. The potential of an area is the total of the destinations in other areas that can be reached from the area discounted by a negative function of the effort to reach them.

Three kinds of potential accessibility indicator are suggested below. The first two measure accessibility to population, the last one accessibility to economic activity (expressed by gross domestic product, or GDP) [10]. Accessibility to population is an indicator for the size of market areas for suppliers of goods and services; accessibility to GDP an indicator of the size of market areas for suppliers of high-level business services.

Potential accessibility is based on the assumption that the attraction of a destination increases with size, and declines with distance, travel time or cost. Destination size usually represents by population or economic indicators such as GDP (gross domestic product). Accessibility to population is seen as an indicator for the size of market areas for suppliers of goods and services; accessibility to GDP an indicator of the size of market areas for suppliers of high-level business services.

Travel time and travel cost indicator give a good impression of the effort to reach other places.

A list of travel time and cost indicators include:

- $\quad$ Link travel time by transport mode or multimodal

- $\quad$ Origin-destination travel times by transport mode or multimodal

- Link travel cost by transport mode or multimodal

- Origin-destination travel costs by transport mode or multimodal and type of traveller

Travel time and travel cost indicator will be presented in numerical form as well as in maps showing indicator values link by link or isochrones or isocosts for selected origins.

The list of indicators includes indicators of the following groups (see Figure 1):

- Indicators describing the supply of transport networks and services,

- Indicators describing the use of transport networks and services,

- Accessibility indicators. 
Transport infrastructure supply indicators can be grouped in two basic categories. Endowment indicators consider the transport infrastructure in an area expressed by such measures as total length of motorways or number of railway stations. Endowment indicators are indicators measuring the suitability of the region for economic activity and may include traditional location factors such as availability of skilled labor and business services, capital stock (i.e. production facilities) and intraregional transport infrastructure as well as 'soft' location factors such as institutions of higher education, good housing and a pleasant climate and environment. Morphological indicators describe features of modal networks and are mainly derived from graph theory or fractal theory. Transport infrastructure capacity indicators can be grouped in two basic types, one describing capacities of links and the other capacities of terminals [10].

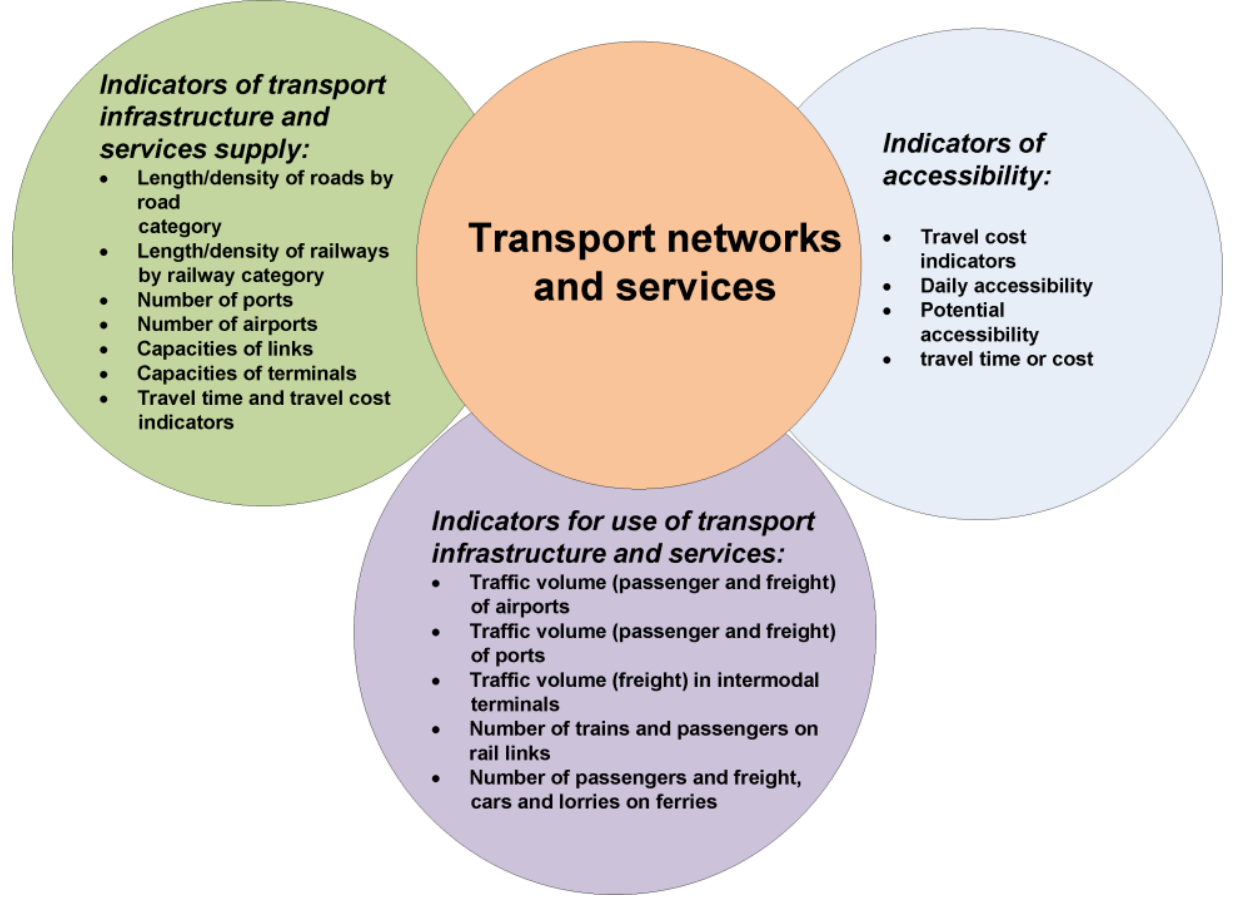

Figure 1. Indicators of transport network, services and accessibility. [39]

Accessibility indicators may be calculated for road, rail, inland waterways or air. Multimodal accessibility indicators combine several modal accessibility indicators. Intermodal accessibility indicators include trips by more than one mode. Accessibility indicators at the continental, transnational or regional scale may require data of different spatial resolution with respect to area size and network representation, intra-area access and intra-node terminal and transfer time. Equity accessibility indicators may be calculated for specific groups of areas in order to identify inequalities in accessibility between rich and poor, central and peripheral, urban and rural, nodal and interstitial areas. Accessibility indicators may be calculate for different points in time in order to show changes in accessibility induced by TEN projects or other transport policies, including their impacts on convergence or divergence in accessibility between areas. Accessibility indicators may be calculate from the point of view of different population groups such as social or age groups, different occupations such as business travellers, tourists or different economic actors such as industries or firms. Accessibility indicators may measure the location of an area with respect to opportunities, activities and assets such as population, economic activities, universities or tourist attractions. The activity function may be rectangular (all activities beyond a certain size), linear (of size) or non-linear (to express agglomeration effects) [38].

The spatial impedance term may be a function of one or more attributes of the links between areas such as distance (Euclidean or network distance), travel time, travel cost, convenience, reliability or safety. The impedance function applied may be linear (mean impedance), rectangular (all destinations within a given impedance) or non-linear (e.g. negative exponential). The use of the links between areas may be constrained by regulations (speed limits, road gradients, maximum driving hours) or by capacity constraints (vehicle size, congestion). In addition to spatial impedance, also non-spatial (e.g. political, economic, legal, cultural or linguistic barriers) between 
areas may be considered. In addition, non-spatial linkages between areas such as complementary industrial composition may be considered.

\section{Dimensions of accessibility indicators}

Accessibility indicators may be sensitive to the following dimensions: origins, destinations, impedance, constraints, barriers, types of transport, modes, spatial scale, equity and dynamics [29]. - Origins: Accessibility indicators may be calculated from the point of view of different population groups such as social or age groups, different occupations such as business travellers or tourists, or different economic actors such as industries or firms.

- Destinations: Accessibility indicators may measure the location of an area with respect to opportunities, activities and assets such as population, economic activities, universities or tourist attractions. The activity function may be rectangular (all activities beyond a certain size), linear (of size) or non-linear (to express agglomeration effects).

- Spatial impedance: The spatial impedance term may be a function of one or more attributes of the links between areas such as distance (Euclidean or network distance), travel time, travel cost, convenience, reliability or safety. The impedance function applied may be linear (mean impedance), rectangular (all destinations within a given impedance) or non-linear (e.g. negative exponential).

- Constraints: The use of the links between areas may be constrained by regulations (speed limits, access restrictions for certain vehicle types or maximum driving hours) or by capacity constraints (road gradients or congestion).

- Barriers: In addition to spatial impedance the non-spatial, e.g. political, economic, legal, cultural or linguistic barriers between areas or non-spatial linkages between areas such as complementary industrial composition may also be considered.

- Types of transport: Only personal travel or goods transport, or both, may be considered.

- Modes: Accessibility indicators may be calculated for road, rail, inland waterways or air. Multimodal accessibility indicators combine several modal accessibility indicators. Inter-modal accessibility indicators include trips by more than one mode.

- Spatial Scale: Accessibility indicators at the continental, transnational or regional scale may require data of different spatial resolution both with respect to area size and network representation, intra-area access and intra-node terminal and transfer time.

- Equity: Accessibility indicators may be calculated for specific groups of areas in order to identify inequalities in accessibility between rich and poor, central and peripheral, urban and rural, nodal and interstitial areas.

- Dynamics: Accessibility indicators may be calculated for different points in time in order to show changes in accessibility induced.

\section{CONCLUSION}

The relationship between transport infrastructure and spatial development has become more complex than ever. Accessibility concepts range from very simple indicators to sophisticated indicators and they can differ in complexity:

- Simple accessibility indicators ("endowment") - take only transport infrastructure in the area itself into account (e.g. length of road, number of railway stations or port or airport existing).

- More complex accessibility indicators - take account of the connectivity of transport networks, distinguish between network itself and the opportunities that can be reached (e.g. travel time to cities, daily accessibility, potential accessibility).

This Paper provides a brief review on existing indicators for transportation networks and services. Any indicator presents just a simplified model of understanding and explaining reality; by definition, they just "indicate" certain aspects of the problem or the concept being studied while other aspects remain dark. Successful indicators, rather than trying to explain everything, have to be focused on key aspects, illuminating those aspects more relevant to the problem under scrutiny. Therefore, multiple indicators, as scientifically consistent and policy-meaningful as feasible, needed to get useful insights [10]. The purpose of the Paper is to show existing indicators and new indicators of accessibility, more complex, scientifically consistent and relevant to contemporary trends on transport. The existing indicators do answer the research questions only to a certain degree. New 
indicators are showing the interrelationships between the supply, trends and impacts of transport infrastructure networks and services and territorial features, such as the degree of polycentrism, accessibility to different types of regions and territories, areas lagging behind, inter- and multimodality and missing links.

Each of the different accessibility types has its own advantages and disadvantages. Travel time indicators and daily accessibility indicators are easy to understand and to communicate though they generally lack a theoretical foundation. Potential accessibility is founded on sound behavioural principles but contain parameters that need to be calibrated and their values cannot be expressed in familiar units.

Accessibility concepts range from very simple indicators to sophisticated indicators and models used in regional science. Different accessibility models used diferent accesibility indicators. Over the last decades, there are a growing number of accessibility models, accessibility studies and project addressing European accessibility. Accordingly, accessibility as an issue has an important role in the European Observation Network, which provides a wide range of indicators that describe the the transportation system and its spatial implications and indicators accessibility. The purpose of the European Observation Network (ESPON) projects is one the one hand updating existing indicators and advancing in new indicators scientifically consistent and relevant to contemporary trends on transport, and on the other, gathering a set of policy. In addition, raster-based maps, time space maps and chronocarts may be considered as a starting point to develop innovative cartographic methodologies as in [10]. Combining the Geographic Information System (GIS) and statistical monitoring results in a framework of statistical-cartographic data and indicators, that can be a suitable base for decision makers.

The existing accessibility indicators used in ESPON, notably in the [10] used a measure of potential accessibility, based on what the existing physical infrastructure could provide in terms of transport flows. Such as in [10], each of the different accessibility type indicators have been calculated and presented for the European territory. The accessibility model based on [4] uses centroids of NUTS-3 regions as origins and destinations. The accessibility model calculates the minimum paths for the road network, i.e. minimum travel times between the centroids of the NUTS-3 regions. For each NUTS-3 region, the value of the potential accessibility indicator is calculate by summing up the population in all other regions including those outside the ESPON space weighted by the travel time to go there. Because the accessibility indicators are in non-familiar units, accessibility is standardised to the average accessibility of the ESPON space.

The other important aspect is the mission of The Organization for Economic Cooperation and Development (OECD, 1998-2000) which investigate current evaluation studies of major transport infrastructure projects in OECD Member countriesi. The aim is to develop guidance for governments and transport administrations on how to identify such impacts and include them in appraisal methodologies in order to improve the efficiency of investment in transport infrastructure. The application of cost benefits analysis in OECD Member countries for this purpose has tended to concentrate on the direct user benefits of transport. However, it was been suggested that transport infrastructure investment has wider impacts on regional development, which range beyond direct user benefits, and these should also be taken into account in order to ensure efficient allocation of resources [39].

This Paper shows that accessibility is an important determinant of the attractiveness of regions and hence and should be taken into account in government policies and transportation planning studies and strategies. Accessibility indicators could be use as part of a spatial monitoring system. Such accessibility indicators could have significant political relevance and could be use in different regional policy contexts. Policies to improve regional accessibility by transport infrastructure investments belong to the most effective policies to stimulate regional competitiveness and economic development [39].

\section{REFERENCES}

1. A. Ribeiro, A.P.Antunes, and A. Páez, "Road accessibility and cohesion in lagging regions: empirical evidence from Portugal based on spatial econometric models", Journal of Transport Geography, vol. 18, pp. 125-132, 2010.

2. B. Linneker, "Transport Infrastructure and Regional Economic Development in Europe: A Review of Theoretical and Methodological Approaches", Report to SASI Project. TRP 133. Sheffield, Department of Town and Regional Planning, 1997.

3. C. Koopmans, P. Rietveld, and A. Huilg, 2012. "An accessibility approach to railways and municipal population growth, 1840-1930", Journal of Transport Geography, vol. 25, pp. 98104,2012 
4. C. Schürman, K. Spiekermann, and M. Wegener, "Accessibility indicators". Berichte aus dem Institut für Raumplanung, 39, IRPUD, Dortmund, 1997.

5. D. Biehl, (Ed.), "The Contribution of Infrastructure to Regional Development", Final Report of the Infrastructure Studies Group to the Commission of the European Communities, Luxembourg: Office for Official Publications of the European Communities, 1986.

6. D. Biehl, "The role of infrastructure in regional development", In R.W. Vickerman (Ed.): Infrastructure and Regional Development, European Research in Regional Science, London, Pion, vol. 1, pp. 9-35, 1991.

7. D. Keeble,' J. Offord, and S. Walker, Peripheral Regions in a Community of Twelve Member States, Luxembourg: Office for Official Publications of the European Communities, 1988.

8. D. Keeble, P.L. Owens, and C. Thompson, "Regional accessibility and economic potential in the European Community", Regional Studies, vol. 16, pp. 419-432, 1982.

9. E. López, J. Gutiérrez, and' G. Gómez, "Measuring regional cohesion effects of large-scale transport infrastructure investments: an accessibility approach", European Planning Studies, vol. 16, no. 2, pp. 277-301, 2008.

10. ESPON 1.2.1, Pransport Services and Networks: Territorial Trends and Basic Supply of infrastructure for Territorial Cohesion, Final Report, Tours: University of Tours, http://www.espon.eu., 2005.

11. F. Bruinsma, and P. Rietveld, "Urban agglomerations in European infrastructure networks", Urban Studies, vol. 30, no. 6, pp. 919-934, 1993.

12. F.P. van den Heuvel, L. Rivera, K. H. van Donselaar, A. de Jong, Y. Sheffi, P.W. de Langen, and J. C. Fransoo,"Relationship between freight accessibility and logistics employment in US counties", Transportation Research Part A, vol. 59, pp. 91-105, 2014

13. G. Chi, "The impacts of highway expansion on population change: an integrated spatial approach", Rural Sociology, vol. 75, no. 1, pp. 58-89, 2010.

14. G. Chi, "The impacts of transport accessibility on population change across rural, suburban and urban areas: a case study of Wisconsin at sub-county levels", Urban Studies, vol. 49, pp. $2711-2731,2012$

15. G. Törnqvist, "Contact Systems and Regional Development", Lund Studies in Geography B vol. 35. Lund: C.W.K. Gleerup, 1970.

16. J. Berechman, "Urban and regional economic impacts of transportation investment: a critical assessment and proposed methodology", Transportation Research Part A, vol. 28 no.4, pp. 351-362, 1994

17. J. Berechman, and R. Paaswell, "Accessibility improvements and local employment: an empirical analysis", Journal of Transportation Statistics, vol. 4, no. 2, pp. 49- 66, 2001.

18. J. Berechmen, D.O'zmen, and K.Ozbay, "Empirical analysis of transportation investment and economic development at state, county and municipality levels", Transportation, vol. 33, pp. 537-551, 2006

19. J. Brö́cker, and K. Peschel, Trade. In W. Molle, R.Cappelin, (Eds.), Regional Impact of Community Policies in Europe, Aldershot: Avebury,1988.

20. C. Martín, J. Gutiérrez, and C. Román, "Data Envelopment Analysis (DEA) Index to Measure the Accessibility Impacts of New Infrastructure Investments: The Case of the High- speed Train Corridor Madrid-Barcelona-French Border", Regional Studies, vol. 38, no 6, pp. 697 $712,2004$.

21. J. Gutiérrez, "Location, economic potential and daily accessibility: an analysis border". Journal of Transport Geography, vol. 9, no. 4, pp. 229-242, 2001.

22. J. Gutiérrez, A. Condeco-Melhorado, and J. C. Martín, "Using accessibility indicators and GIS to assess spatial spillovers of transport infrastructure investment", Journal of Transport Geography, vol. 18, pp. 141-152, 2010.

23. J. Gutiérrez, R. González, and G. Gómez, "The European high-speed train network: predicted effects on accessibility patterns", Journal of Transport Geography, vol. 4, pp. 227-238, 1996.

24. J. M. Morris, P.L.Dumble, and' M.R. Wigan, "Accessibility indicators for transportation planning", Transportation Research A, vol. 13,pp. 91-109, 1979.

25. K. Ozbay, D. Ozmen, and J.Berechman, "Modeling and analysis of the link between accessibility and employment growth", Journal of Transportation Engineering, vol. 132, no. 5,

26. K. S. 385-393, 2006 . Europe", European Journal of Regional Development, vol. 4, pp. 35-42, 1996.

27. K.T. Geurs, and B. van Wee, "Accessibility of land-use and transport strategies: review and research directions", Journal of Transport Geography, vol. 12, pp. 127-140, 2004.

28. K.T. Geurs, and J.R.' Ritsema van ECk, "Accessibility measures: review and applications", RiVM Report 408505 006, National Institute of Public Health and the Environment, Bilthoven, 2001.

29. M. Wegener, H. Eskelinnen, F. Fürst, C. Schürmann, and K. Spiekermann, "Criteria for the Spatial Differentiation of the EU Territory: Geographical Position", Forschungen 102.2, Bonn: Bundesamt für Bauwesen und Raumordnung, 2002.

30. P. Gould, "Spatial Diffusion", Resource Paper No. 17, Washington, DC: Association of American Geographers, 1969.

31. P. Jiwattanakulpaisarn, R.P. Noland, and D.J. Graham, "Causal linkages between highways and sector-level employment", Transportation Research Part A, vol. 44, pp. 265-280, 2010.

32. R.J. Johnston, D. Gregory, G.'Pratt, and M. Watts, The Dictionary of Human Geography, Oxford, Blackwell Publishing, 2000.

33. R. Thompson, and E. Taniguchi, "City logistics and freight transport", In: A.M. Brewer, K.J. Button, D.A. Hensher, (Eds.), The Handbook of Logistics and Supply-Chain Management, Handbooks in Transport, no 2. Pergamon, Elsevier, London, pp. 393-404, 2001. 
34. R. W. Vickerman, "Accessibility, attraction, and potential: a review of some concepts and their use in determining mobility", Environment and Planning A vol. 6, pp. 675-691, 1974.

35. R.W. Vickerman, Introduction. 'In R.W. Vickerman (ed.), Infrastructure and Regional Development, London: Pion, pp. 1-8, 1991a.

36. S.L. Handy, and D.A. Niemeier, "Measuring Accessibility: An Exploration of Issues and Alternatives", Environment and Planning A, vol. 29, pp. 1175-94, 1997.

37. S. Karou, and A. Hull, "Accessibility modelling: predicting the impact of planned transport infrastructure on accessibility patterns in Edinburgh, UK", Journal of Transport Geography, vol. 35, pp. 1-11, 2014 .

38. Study Programme on European Spatial Planning Working Group, 1.1 GEOGRAPHICAL POSITION Final Report Part 1, Prepared by the National Focal Points of Finland, France and Germany Draft 12, January 2000.

39. T. Kramberger, V. Potočan, \& V. M. Ipavec, Sustainable Logistics and Strategic Transportation Ṕlanning, University of Maribor, Slovenia, pp. 248-272, ISBN13: 9781522500018; EISBN13: 9781522500025, DOl: 10.4018/978-1-5225-0001-8.ch012, 2016.

40. U.Blum, "Effects of transportation investments on regional growth: a theoretical and empirićal investigation", Regional Science Association vol. 49, pp. 169-184, 1982.

41. J.Hong, "Transport and the location of foreign logistics firms: the Chinese experience", Transportation Research Part A, vol. 41, pp. 597-609, 2007.

AUTHOR

A. Ana Vulevic is with the Institute of Transportation CIP, Department of Architecture and Urban Planning, Belgrade, Serbia (email: anavukvu@gmail.com). 